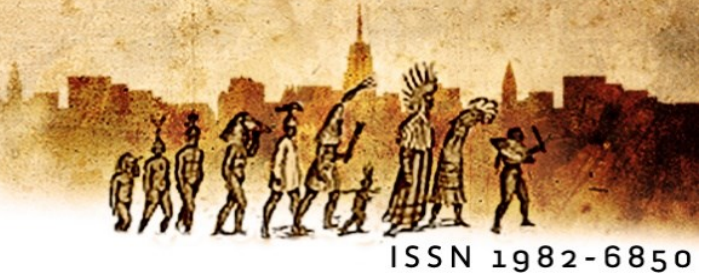

\title{
Problemas metodológicos para a análise de textos históricos: o caso "Fusca" (1950-1970)
}

\section{Methodological problems for the analysis of historical texts: the "Fusca" case (1950-1970)}

\author{
Diego Bussolai (Universidad Nacional de Rosario) \\ Florencia Mirandaii (Universidad Nacional de Rosario)
}

Resumo: O objetivo deste trabalho é observar alguns problemas metodológicos que se colocam para a análise de textos históricos. Entendemos por "textos históricos" aqueles que, sendo objeto empírico de análise em uma pesquisa, foram produzidos e circularam originalmente em condições sociotemporais diferentes às da contemporaneidade do analista. No trabalho identificamos os seguintes problemas: a contextualização, a confiabilidade, o possível olhar anacrônico e a conformação do corpus. A problematização é desenvolvida a partir de um exemplo concreto: o caso das campanhas publicitárias de um carro da Volkswagen no Brasil nas décadas de 1950 e 1960 - exemplo esse que denominamos "o caso «Fusca»". No presente trabalho assumimos a perspectiva teórica-epistemológica do Interacionismo Sociodiscursivo (BRONCKART et al. 1985; BRONCKART 1997, 2008; entre outros). A finalidade última do nosso artigo é aportar elementos para a construção de um desenho metodológico adequado para a análise de textos históricos (e para a análise da historicidade de gêneros textuais) no quadro do projeto HISTEL.

Palavras-chave: textos históricos; metodologia da pesquisa; corpus; análise descendente; Interacionismo Sociodiscursivo

Resumen: El objetivo de este trabajo es observar algunos problemas metodológicos que se plantean para el análisis de textos históricos. Entendemos por "textos históricos" los que, siendo objeto empírico de análisis en una investigación, se produjeron y circularon originalmente en condiciones socio-temporales diferentes a las de la contemporaneidad del analista. En el trabajo identificamos los siguientes problemas: la contextualización, la confiabilidad, la posible mirada anacrónica y la conformación del corpus. La problematización se desarrolla a partir de un ejemplo concreto: el caso de las campañas publicitarias de un automóvil de Volkswagen en Brasil en las décadas de 1950 y 1960 - ejemplo que 
denominamos "el caso «Fusca»". En el presente trabajo asumimos la perspectiva teórica-epistemológica del Interaccionismo Sociodiscursivo (BRONCKART et al., 1985; BRONCKART, 1997, 2008; entre otros). La finalidad última de nuestro artículo es aportar elementos para la construcción de un diseño metodológico adecuado para el análisis de textos históricos (y para el análisis de la historicidad de géneros textuales) en el marco del proyecto HISTEL.

Palabras clave: textos históricos; metodología de la investigación; corpus; análisis descendente; Interaccionismo Sociodiscursivo

\section{Introdução}

O presente artigo dialoga com outros trabalhos publicados nesta mesma Revista, cujos autores participam do Projeto de Pesquisa "Historicidade dos textos e ensino de línguas (HISTEL)". A nossa contribuição para este diálogo diz respeito a questões de ordem metodológica, necessárias para empreender um estudo sobre textos que podem ser chamados de "históricos". Assim, o objetivo de nosso trabalho é identificar um conjunto de problemas metodológicos que se podem colocar no desenvolvimento de uma pesquisa que proponha a análise de "textos históricos". Utilizamos esta expressão para referir o caso de textos que, sendo objeto empírico de análise em uma pesquisa, foram produzidos e circularam originalmente em condições sociotemporais diferentes (e anteriores, como é óbvio) às da contemporaneidade do analista. Esta observação inicial é importante, já que a designação utilizada não implica assumir que os textos da atualidade não sejam também "históricos", mas neste caso adotamos tal denominação para marcar a relação de nãocontemporaneidade entre o analista e os textos.

Para avançar na identificação dos problemas que nos interessam, comentaremos um caso singular de pesquisa, ao qual damos o nome de caso "Fusca". Este exemplo permitirá mostrar alguns dos aspectos mais relevantes que consideramos preciso levar em conta para desenvolver qualquer estudo que parta da análise de textos históricos.

Iniciaremos o artigo situando nossa perspectiva teórica-epistemológica, contextualizando o caso que tomaremos como exemplificador e colocando o problema central que selecionamos para esta exemplificação. Depois, apresentaremos o percurso metodológico que tivemos de realizar para avançar na pesquisa e mostraremos alguns dos dados principais recolhidos nesse caminho. Finalmente, proporemos uma síntese e 
sistematização dos problemas levantados e das soluções que fomos encontrando em nossa pesquisa.

\section{Perspectiva teórica e apresentação de uma pesquisa}

Para a abordagem de problemas socio-históricos e de linguagem, situamos nosso estudo globalmente no quadro teórico-epistemológico e metodológico do Interacionismo Social (VOLOSHINOV, 2009 [1929]) e, mais especificamente, no Interacionismo Sociodiscursivo (BRONCKART et al., 1985; BRONCKART, 1997, 2008; entre outros). Assim, assumimos que para a compreensão dos acontecimentos socio-históricos e de linguagem é preciso observar os produtos semióticos da atividade humana (textos e discursos) em seu ambiente de produção e circulação original, de maneira a poder observar os fatores que participam em (e condicionam) sua conformação.

Neste sentido, adotamos o percurso metodológico "descendente" proposto por Voloshinov (2009 [1929], p.155) e retomado por Bronckart (2004). Esse percurso implica partir da observação das atividades sociais ou coletivas, realizando uma análise do quadro socio-histórico e situacional, passar pela identificação e caracterização dos gêneros textuais que organizam a semiotização, para a partir daí, observar o funcionamento e o papel dos elementos linguísticos mobilizados no texto. Ou seja, a abordagem descendente propõe um caminho que vai da prática social para a configuração linguística. Portanto, precisamos identificar aspectos relevantes da situação de produção do texto e do contexto sóciohistórico em que ele se constitui e, também, precisamos compreender o texto como uma unidade complexa, aberta e dinâmica (no sentido de Bernárdez (1995) e Miranda (2010)), que dialoga necessariamente com os discursos e os textos do seu tempo.

A pesquisa que tomamos como exemplo para trazer a problematização metodológica que propomos visa ao estudo das publicidades e campanhas publicitárias de um carro da Volkswagen que teve uma importante presença e difusão no Brasil na segunda metade do século XX: o carro que ficou conhecido como "Fusca". Os dados para a nossa análise são textos publicitários publicados no Brasil entre 1950 e 1970, abrangendo partes do Período democrático (1945-1964) e da Ditadura militar (1964-1985) (FAUSTO, 1995). 
A seguir, apresentaremos de forma breve alguns dos problemas metodológicos que fomos encontrando no início da nossa pesquisa, com o intuito de trazer contribuições concretas para o estudo de problemas históricos e sobre "textos históricos".

\section{Problemas metodológicos}

Para iniciar esta problematização, vale a pena mencionar que nas últimas décadas muitos estudos sobre textos partem de uma busca de exemplares na internet. De fato, isto resulta possível porque, tal como afirma Serres (2013), com a expansão do uso da internet podemos dizer que atualmente "tudo" está disponível na www (World Wide Web). Assim, quando o autor reflete sobre o ensino e o saber nas primeiras décadas do século XXI, coloca o problema nestes termos: "O que transmitir? O saber? Ele está agora por todo lugar, na internet, disponível, objetivado. Transmiti-lo a todos? O saber inteiro passou a estar acessível a todo o mundo. Como transmitir? Pronto, é coisa feita" (SERRES, 2013, p.26). No caso da publicidade (e dos anúncios, em particular) encontramos inúmeros sites com grande quantidade de publicidades, recortadas de seus suportes originais, reorganizadas geralmente (e no melhor dos casos) de forma cronológica - embora também se verifiquem outros critérios como, por exemplo, temáticos e ideológicos. Também em Pinterest, por exemplo, há conjuntos de publicidades retiradas de jornais e revistas que se encontram como "Publicidades antigas"1. E ainda existe um site dedicado a reunir publicidades brasileiras com o nome de "propagandas históricas" ${ }^{2}$. Os textos que se reproduzem nestes sites podem ter alguma indicação da fonte (de forma mais ou menos vaga) ou não ter nenhuma informação.

Se levarmos a reflexão de Serres acima citada para o campo da metodologia da pesquisa, podemos concordar em que não há dúvidas de que existe muita informação disponível na internet. Infinidade de textos e imagens que permitiriam avançar em infinitas pesquisas na área das ciências sociais e humanas, ou seja, no estudo das práticas humanas e acontecimentos atuais e passados e nas formas de semiotização. Todavia, o mero acesso a textos e imagens não garante um avanço possível para uma pesquisa sólida e rigorosa. Nesse

${ }^{1}$ https://br.pinterest.com/flavinhoo/publicidade-antiga/; https://br.pinterest.com/alexrosanag0482/propagandas-antigas/

${ }^{2}$ https://www.propagandashistoricas.com.brl 
sentido, é preciso identificar algumas questões problemáticas que se colocam numa pesquisa em torno de textos históricos (e não só).

Em primeiro lugar, o sério problema da contextualização. Com efeito, na internet encontramos "tudo", mas a forma em que essa informação é apresentada coloca um problema concreto para a pesquisa: em geral, os textos reproduzidos foram retirados de sua publicação original, de maneira que já não contam com dados sobre a publicação (nome do jornal ou revista, data e número de página), nem sobre o contexto de publicação (situação socio-histórica de produção e circulação, espaço que ocupava a publicidade na publicação original, relação do texto com os outros textos, etc.). Como é evidente, um primeiro problema metodológico que essa situação coloca aos pesquisadores interacionistas é que partindo desses textos recortados de seu contexto de circulação original, não é possível realizar uma abordagem descendente (VOLOSHINOV, 2009 [1929]; BRONCKART, 2004)3. Qual era a situação social, histórica e cultural no momento e local de produção? Quem e para quem produziu esse texto? Como esse texto dialogava com os textos e discursos da época e da sociedade em questão? É impossível observar profundamente estes aspectos (e ainda outros) sem contar com conhecimentos pertinentes em relação a esse contexto de produção e circulação original dos textos.

Ao problema da contextualização podemos ainda somar, nos casos em que alguma fonte é mencionada nos sites, a confiabilidade da informação fornecida. De fato, um blogue criado por uma pessoa interessada nas publicidades antigas, por exemplo, não está submetido a normas de indicação rigorosa da fonte - como acontece, sim, no âmbito da escrita acadêmica e científica. De maneira que, mesmo que fossem indicados diversos dados da publicação original, sempre ficará a dúvida da fiabilidade dessa informação.

Além disso, considerando que os sites que disponibilizam textos costumam apresentar muitos exemplares, alguém poderia assumir que cada site traz um corpus ou vários corpora prontos para desenvolver pesquisas. Contudo, pensamos que não é possível defender essa ideia, já que na constituição desses bancos de textos mais ou menos

\footnotetext{
3 É claro que se podem analisar textos que circulam desligados do seu contexto original justamente para falar sobre essa circulação relocalizada ou recontextualizada; mas quando o foco está colocado no texto enquanto amostra de uma produção histórica esse novo contexto de circulação (um site da internet, por exemplo) não é suficiente para realizar uma análise do processo de produção do texto, nem do texto ligado ao contexto original de produção.
} 
organizados não há critérios (de seleção e de representatividade, entre outros) no processo de recolha e também porque, como dissemos, não se pode ter acesso a informações confiáveis sobre os dados de publicação original. Por isso, para conformar e organizar um corpus consistente para uma pesquisa, defendemos a necessidade de se fazer uma procura de textos controlada e com critérios claros em um determinado arquivo documental.

Na última década, impulsionado pela sistemática digitalização de arquivos, abriu-se uma nova possibilidade de consulta à distância de fundos documentais. Desta forma, a consulta em arquivos, em muitos casos pode ser realizada online, com a possibilidade de ler e/ou baixar o material à distância. É o caso da Hemeroteca Digital do Brasil, que está disponível online e em funcionamento desde há 10 anos, contando com um acervo importante de jornais e revistas 4 . Assim, no caso que mostraremos no presente trabalho, realizamos um levantamento exaustivo na Hemeroteca Digital do Brasil, procurando na revista Manchete e em outras publicações periódicas. O corpus para esta análise preliminar está constituído por publicidades do carro sedan da Volkswagen na revista Manchete entre 1959 e 1970 e em outros jornais e revistas na década de 1950. Além dos critérios que dizem respeito ao gênero textual (anúncio publicitário), o suporte (determinadas revistas e jornais) e a data de publicação (período 1950-1970), observamos também quem era o anunciante dos textos (Volkswagen do Brasil ou outro) e classificamos os exemplares do corpus em subgrupos levando em consideração essa informação.

Um último problema metodológico que mencionaremos por enquanto é aquele que chamamos de problema do olhar anacrônico. Isso significa a possibilidade de alguém fazer uma leitura do passado mobilizando representações do presente. Nesse sentido, a análise de textos históricos deve conscientizar a necessária dificuldade de análise e interpretação que implica ler um texto que foi produzido em outro momento socio-histórico. No caso dos textos publicitários esta dificuldade se acrescenta quando se trata, por exemplo, de um produto conhecido no presente do pesquisador, mas que na época de produção e circulação original dos textos era um produto novo. Na pesquisa sobre publicidades de um carro, que mostramos aqui como exemplo, este foi um dos aspectos que era especialmente necessário observar.

${ }^{4}$ https://bndigital.bn.gov.br/hemeroteca-digital/ 
Quando iniciamos o nosso estudo, fizemos um pequeno experimento. Pedimos a um conjunto de colegas (professores de português na Argentina de diferentes idades, alguns sendo brasileiros e outros argentinos) que observassem as imagens que reproduzimos na figura 1 e que dissessem o que eram esses textos. A maior parte dos consultados respondeu que eram publicidades do "Fusca". Outros - os mais novos - disseram que eram publicidades de "um carro".

\section{Figura 1 - Publicidades da Volkswagen (décadas 1950-1960)}

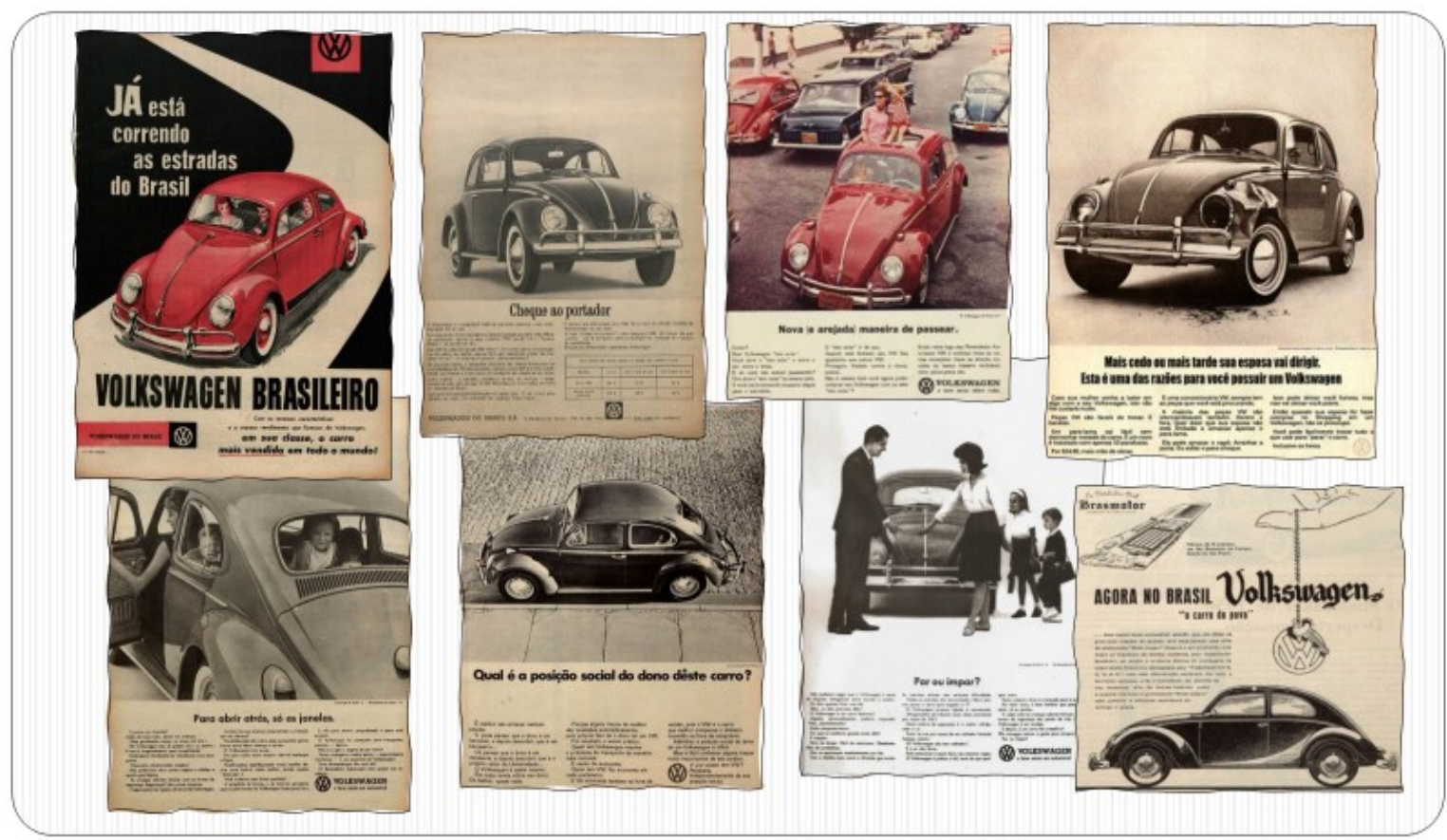

Fonte: https://www.propagandashistoricas.com.br; https://br.pinterest.com/flavinhoo/publicidade-antiga/i https://br.pinterest.com/alexrosanago482/propagandas-antigas/

O que observamos no nosso pequeno experimento é que essas afirmações se sustentam em uma "competência cultural", um saber e uma experiência, que envolve duas variáveis: por um lado, o vínculo com determinado espaço geográfico e social que poderíamos nomear como "Brasil"; e, por outro lado, a variável temporal, isto é, o fato de as pessoas consultadas terem atravessado ou não parte de sua idade adulta na segunda metade do século XX. Em particular, observamos que a competência cultural das pessoas que responderam que se trata de anúncios de um "Fusca" está ligada ao conhecimento de aspectos socioculturais do Brasil até os anos 9o. De fato, os professores mais novos não mencionaram a palavra "fusca". Se a experiência fosse replicada com pessoas nascidas 
depois do ano 2000 no Brasil, é muito provável que algumas delas respondessem da mesma forma que os colegas argentinos mais novos.

Ora bem, observada essa questão em perspectiva histórica, os textos que mostramos nas imagens não são, em rigor, anúncios do "Fusca". De fato, a palavra fusca não é mencionada em nenhum deles. Parece importante, neste ponto, explicitar que os nomes que damos aos objetos que nos rodeiam são sempre construções históricas. Se nós hoje podemos reconhecer um "Fusca" nesses anúncios, na época em que os textos se produziram e circularam não era um "Fusca" o que viam os leitores contemporâneos. Ainda a forma de ler e designar o que é um anúncio publicitário, o que é um carro e o (re)conhecimento da marca Volkswagen constituem construções históricas. Tanto Volkswagen quanto "fusca" são significantes que se constroem e se estabilizam como signos no Brasil durante o período sobre o qual trabalhamos (1950-1970). É este caso particular do nome do carro (que é objeto dos anúncios) que decidimos explorar em um primeiro momento da pesquisa e que aqui trazemos como exemplo.

\section{O caso "Fusca"}

Uma das primeiras tarefas que nos propusemos no início de nossa pesquisa foi encontrar em que momento começou a ser comercializado o carro da Volkswagen e qual foi a primeira publicidade do carro. Em uma pesquisa na Hemeroteca Digital do Brasil encontramos que o primeiro anúncio publicitário é de dezembro de 1950. Paralelamente, encontramos uma série de notícias que permitiam compreender a procedência dessas publicidades e o contexto. Na análise do primeiro anúncio verificamos duas coisas: por um lado, que a palavra "Fusca" não ocorre nos textos e, por outro lado, que os anúncios dessa época ensinam como a marca do carro deve ser pronunciada na versão aportuguesada do termo (ver figura 2).

Figura 2 - Primeira publicidade do carro da Volkswagen 


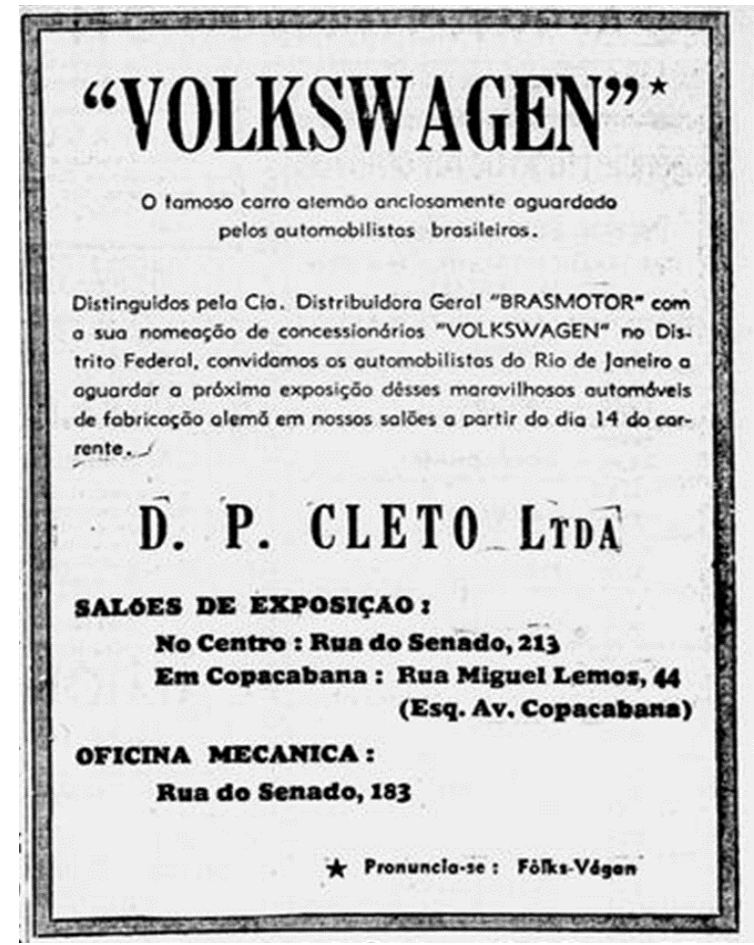

Fonte: JORNAL DO BRASIL, 10-12-1950, p.15.

A partir dessa constatação, decidimos avançar para dar resposta aos seguintes questionamentos: Nas publicidades, esse carro é chamado de "Fusca"? Em caso afirmativo, a partir de quando e de que maneira se usa? Isto nos levou a ter de identificar também quando começa a ser usado o termo "Fusca" para designar esse carro, fora das publicidades.

O que vamos apresentar a seguir é uma síntese dos dados obtidos no caminho percorrido para a construção de uma cronologia acerca das formas de denominação do carro objeto da publicidade. Inicialmente, a análise dos anúncios do nosso corpus e de textos de outros gêneros referidos à marca alemã dos primeiros anos (1950-1959) nos permitiu, por um lado, compreender o contexto de comercialização e venda dos carros (quem produzia, quem distribuía e quem vendia o carro); e, por outro lado, o próprio processo de denominação para chegar ao termo "Fusca" posteriormente consolidado.

Para analisar o contexto de produção das publicidades, um aspecto que foi preciso identificar é quem era o anunciante desses textos. Nesse sentido, verificamos uma lacuna na bibliografia sobre a história da Volkswagen no Brasil, que foi necessário preencher para compreender melhor este primeiro momento. Desde a chegada dos carros importados (finais do ano de 1950) até a montagem no Brasil dos primeiros carros (finais de 1954) a informação 
é parcelar e pouco sistematizada na bibliografia (BRICK, 2006; WOLFE, 2010; KOPPER, 2017; SILVA, 2020; entre outros). Assim, para complementar a informação bibliográfica, o procedimento realizado foi uma procura sistemática em jornais desse período, a partir da palavra Volkswagen; observando tanto artigos jornalísticos quanto anúncios publicitários 5 . Nesse processo, foram consultados jornais do Rio de Janeiro, como o Correio da Manhã, Diário Carioca e Jornal do Brasil, entre outros. A informação que sintetizamos a seguir é produto desse momento da pesquisa.

Em 1950, a VW começa a exportar carros para a América do Sul. Em uma notícia do mês de maio, o Diário Carioca destaca a chegada desses automóveis ao Brasil e à Argentina:

(...) em recente viagem feita à América do Sul pelo sr. Heinz Nordhoff, diretor da empresa que fabrica os micro-automóveis, foram feitos numerosos pedidos e a companhia espera exportar entre dez e quinze mil carros no curso do ano corrente.

Assinalou o informante que as primeiras remessas dos "Volkswagen" serão efetuadas antes de 30 dias, sendo que a maior parte dos carros irá para a Argentina e Brasil. (DIARIO CARIOCA, 24-5-1950, p.5)

Na época, os carros à venda no Brasil eram de maior tamanho do que o Volkswagen e, portanto, daí provavelmente a denominação de "micro-automóvel" para o carro de fabricação alemã, conhecido no seu país de origem como o "carro do povo".

Os carros e o furgão da Volkswagen começam a ser importados e distribuídos pela Brasmotor Ltda., e vendidos em diferentes concessionárias ao longo do país. As primeiras publicidades dos produtos da Volkswagen eram feitas pelas concessionárias como a Cleto Ltda (no Rio de Janeiro), a COMARSA (em Manaus), etc. nos diferentes jornais (Jornal do Comércio e Correio da Manhã, Rio de Janeiro; Jornal do Comércio, Manaus, entre outros). A partir de 1951 a Brasmotor também começa a publicitar estes produtos e o serviço de reparação e manutenção garantida para todos os produtos Volkswagen. Este modo de publicitar os produtos da Volkswagen parece permanecer até 1959, ano em que a Volkswagen do Brasil aparece como responsável pelas publicidades.

\footnotetext{
${ }^{5}$ Nesta procura não foram considerados os anúncios classificados.
} 
Em finais de 1950, na segunda seção do Jornal do Brasil, na parte de anúncios de carros, a distribuidora Cleto Ltda. anuncia pela primeira vez a exposição dos Volkswagen no Rio de Janeiro a partir do dia 14 de dezembro. Nesse anúncio (figura 2), ainda é destacada a forma em que se pronuncia o carro: "Folks-vágen". Nos anúncios posteriores já é incorporado um desenho do carro e, posteriormente, um casal feliz dentro dele. A descrição inclui traços próprios das características do carro: "Volkswagen (o famoso carro alemão). Acha-se agora a venda no Distrito Federal. Um fenómeno de economia (13,5 kms por litro); durabilidade excepcional (aço alemão); linhas modernas; serviço mecânico eficiente; abundante stock de peças sobressalentes" (JORNAL DO BRASIL, 7-1-1951, p.15). A partir de abril de 1951 a Cleto Ltda. deixa de indicar como se deve pronunciar o carro que vendem (JORNAL DO BRASIL, 14-1951, p.15) e, como acima indicado, as publicidades começam a ser mais apelativas.

Além dos anúncios da Cleto Ltda., começaram a surgir publicidades de outras concessionárias no Rio de Janeiro, existindo, assim, uma diversidade de anúncios. A concessionária Auto-modelo, por exemplo, salienta em um anúncio que "Volkswagen - não é um carro grande mas é um grande carro", destacando a sua qualidade por cima do seu tamanho (CORREIO DA MANHÃ, 9-11-1952, p.8). Por outro lado, a Mauricio \& Brito Ltda. é a primeira a incorporar em um anúncio publicitário de jornal uma fotografia junto às seguintes palavras: "Volkswagen. O carro incomparável da maior fábrica da Europa. Económico. Veloz. Confortável" (CORREIO DA MANHÃ, 17-5-1953, p.10).

O que vemos nesta primeira década, é que se verifica uma diversidade de formas de chamar os produtos da Volkswagen, o que deve ser relacionado com a diversidade de anunciantes. Quer a distribuidora, a Brasmotor, quer as diferentes concessionárias utilizavam as formas que consideravam mais apelativas, verificando-se que nestes primeiros anos apenas a marca e a associação com o carro vai se incorporando na sociedade: "O Volkswagen". O que também identifica os carros é o logotipo da marca usado pelas concessionárias (AUTOMÓVEL CLUBE, junho 1958, p.25).

Para compreender esse contexto de produção foi necessária uma procura sistemática em jornais, uma vez que se tivéssemos dito que as publicidades eram da Volkswagen teríamos incorrido em um erro, em um anacronismo, já que o enunciador-anunciante era outro. Só a partir de 1959 começaram a ser desenvolvidas as campanhas da Volkswagen do Brasil e, portanto, só a partir dessa data se pode afirmar que o anunciante é a Volkswagen. 
Em janeiro de 1959, pela primeira vez a Volkswagen do Brasil lança em diversas revistas uma única publicidade anunciando a chegada do "Volkswagen Brasileiro" (figura 3).

Figura 3 - Volkswagen Brasileiro

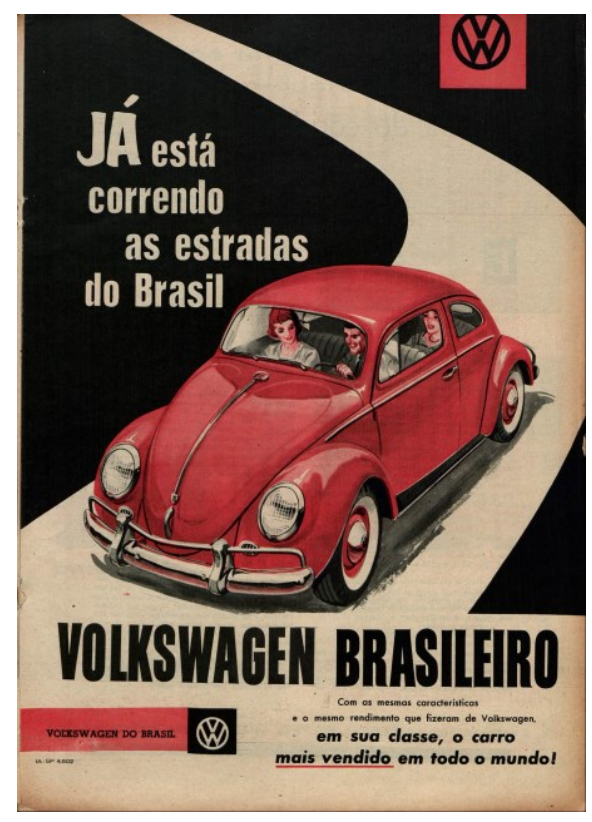

Fonte: MANCHETE, 17-1-1959, p.43.

Depois de um ano e meio sem publicidade, a partir de meados de 1960, a Volkswagen do Brasil começa a publicitar os seus modelos: A "Kombi Volkswagen" e o "Volkswagen", este último em referência ao sedan. Note-se que para nomear o carro era utilizado o nome da marca, ficando identificado como "O Volkswagen". Neste momento, começa a ser usado o slogan "O bom senso em automóvel" que acompanhava o logotipo VW (MANCHETE, 11-61960, p.45).

Embora o logotipo e a marca já estivessem consolidadas no uso, ainda a palavra "fusca" não era utilizada. Para compreender quando começou a ser utilizada foi necessário fazer uma procura na revista Manchete e em outras publicações periódicas da época para conhecer mais sobre esta forma de denominação. Paralelamente, encontramos que em 1962, já havia uma referência a forma em que se pronunciava a marca, diferente da que propunha aquela primeira publicidade de 1950 (fig.2). Assim, uma década depois, em um artigo na revista Manchete intitulado "Um novo idioma nasce no morro", se destacam as formas em que os mecânicos costumam falar com especial destaque para marcas dos carros, mostrando a singularidade do falar carioca para essas marcas: "O senhor tem que comprar um carro 
nacional como Erovílis (Aero-Willys) ou Folksváguener (Volkswagen) e deixar êsses Doja (Dodge), Primus (Plymouth), Crasla (Chrysler) e Ondesmobil (Oldsmobile)." (MANCHETE, 4-8-1962, p.94). Isto exemplifica uma das formas de chamar o carro da Volkswagen na fala carioca.

Junto com esta forma de nomeação se verifica que começa a ser utilizada a palavra fusca (e fusquinha) em textos jornalísticos. Deste modo, em julho de 1962, em um artigo intitulado "Como ser esnobe" é destacado "(...) manter-se atualizado em matéria de moda, música popular e, principalmente, dos mexericos, usando os termos "patins" e "babau". Saber que "Fusca" fica melhor quando você falar em Volkswagen" (A TRIBUNA, 13-7-1962, p.2). Em um regime semelhante, no artigo "Sonho de Fusca", Sérgio Pereira exprime: "o Volkswagen já é dos carros nacionais, o mais procurado, e não há um só rapaz e môça (transviados ou não), que não sonhe ter um. O carrinho ficou tão conhecido que uma nova nomenclatura automobilística foi criada. Ninguém tem mais um Volkswagen, ou se tem um Fusca (corruptela) ou um Volks (diminutivo carinhoso)." (REVISTA DA TRIBUNA, 2-8-1962, p.7). Na Manchete do mesmo ano, na seção de eventos e informações sociais, vemos o artigo intitulado "Tanit é ótima Chauffese", em que se descreve uma moça da alta sociedade: "Ela é filha do conhecido industrial António Sánchez Galdeano (...) Tanit adora guiar automóvel. (...) Chama o seu Volkswagen de "Fusquinha" e fica muito triste se uma batida Ihe amassa o paralama. Tanit tem 18 anos" (MANCHETE, 3-11-1962, p.52). Estes exemplos mostram que, em 1962, a palavra Fusca já circulava na imprensa, fundamentalmente ligada às expressões utilizadas pela sociedade carioca. Ao mesmo tempo, o carro era chamado de outras formas como "volks", "folksváguener", ou "fusquinha".

Apesar deste uso verificado em 1962, foi apenas em 1968 que as publicidades da Volkswagen do Brasil começaram a incluir a palavra Fusca. Assim, verificamos que em julho deste ano uma publicidade da Volkswagen do Brasil destaca "É por isso que tem tanta mulher dirigindo um "Fusca" por ai" (MANCHETE, 6-7-1968, p.36). É importante sublinhar que as primeiras ocorrências do termo nas publicidades se verifica com aspas: "Fusca". Este procedimento demonstra que a publicidade toma esse termo de alguma outra fonte, em um processo de citação. As aspas assinalam um distanciamento enunciativo que nos faz ver que não se trata da autoria própria do nome. Com efeito, os anúncios estão ecoando um nome que nasceu fora da responsabilidade do anunciante e fora do próprio âmbito publicitário. 
Só dois anos mais tarde, em 1970, encontramos anúncios em que se utiliza o termo fusca sem aspas, como por exemplo: "Quem tem outro carro continua com o Fusca atrás da orelha" (Figura 4). Poderíamos dizer que há nesse momento uma apropriação publicitária do nome. De fato, como vimos, o termo fusca nasceu no uso popular. Primeiro, como marca de esnobismo e, depois, como uso coloquial mais expandido (um exemplo desse uso pode ser visto na música "País tropical" de Jorge Ben Jor, do ano 1969... "tenho um fusca e um violão..."). A partir da expansão no uso, o termo foi incorporado pelas publicidades.

Um outro dado interessante, nesse sentido, pode ser observado no mesmo ano 1970, quando se introduz no mercado o carro VW 1500. Nos anúncios de apresentação desse novo produto, vemos a introdução do nome Fuscão, utilizado sem aspas, para denominar o carro: Neste caso, o nome foi certamente uma criação publicitária, elaborada a partir do procedimento comparativo: o Fusca é o VW 1300, o novo carro com motor maior (1500) deve ser chamado de Fuscão.: "Fuscão. O VW já nasceu com apelido: Fuscão. Um Super-Fusca. Êle é realmente um Fusca que ficou ainda mais nervoso, mais brabo (brabo com b). (...) VW 1500" (Figura 5). Assim, ambos os nomes realizam caminhos de instituição diferentes. Fusca vai da rua para a publicidade e Fuscão da publicidade para a rua. 
Figura 4 - Fusca

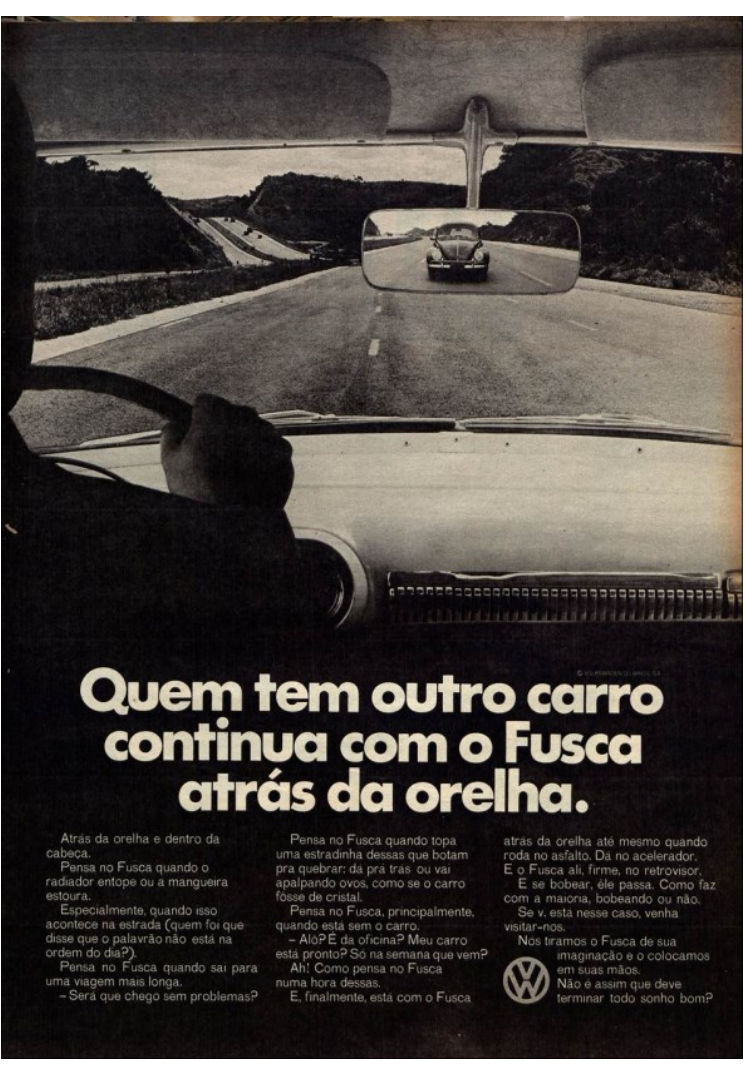

Fonte: MANCHETE, 30-5-1970, p.53.
Figura 5 - Fusção

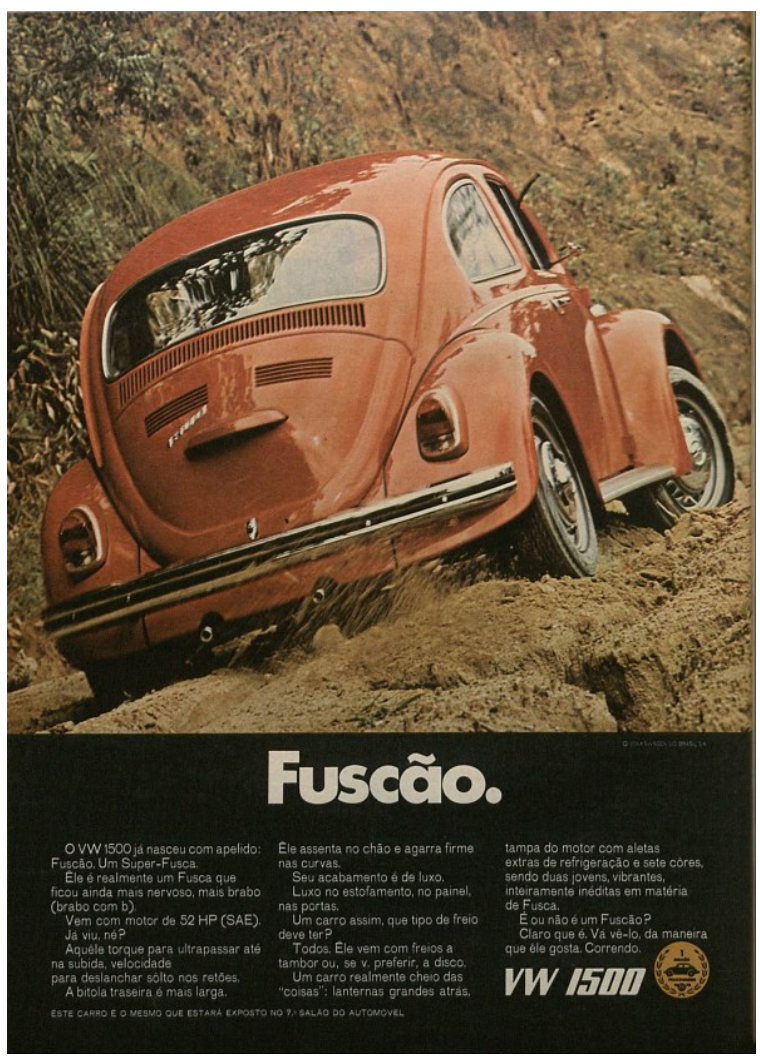

Fonte: MANCHETE, 26-9-1970, p.138.

Finalmente, vale a pena comentar que ambos os termos (fusca e fuscão) aparecem dicionarizados na década de 1980, como se pode verificar no Dicionário Aurélio de 1986 :

fusca. S.m.Bras. Pop. Automóvel Volkswagen de motor de 1200 ou 1300 cilindradas; fusquinha [...]

fuscão. [Aum. de fusca] S.m. Bras. Pop. Automóvel Volkswagen de motor de 1500 cilindradas.(FERREIRA, 1986)

Para fechar esta exposição, apresentamos a síntese da cronologia (tabela 1) construída a partir da análise dos textos do corpus e da busca documental realizada para compreender os processos de comercialização e difusão do carro.

Tabela 1 - Cronologia da Volkswagen no Brasil (1950-1970) 


\begin{tabular}{|l|l|l|}
\hline Data & Nome & \multicolumn{1}{c|}{ Informação } \\
\hline 1950 & Volkswagen & $\begin{array}{l}\text { O carro Volkswagen é importado da Alemanha. } \\
\text { Anunciante (1950-1959): as diversas } \\
\text { concessionárias. }\end{array}$ \\
\hline 1959 & "O Volkswagen brasileiro" & $\begin{array}{l}\text { O carro começa a ser produzido no Brasil. } \\
\text { Anunciante (1959-1970): Volkswagen do Brasil. }\end{array}$ \\
\hline 1962 & Volkswagen & $\begin{array}{l}\text { Há registro dos primeiros usos da palavra Fusca } \\
\text { em textos jornalísticos. }\end{array}$ \\
\hline 1968 & "Fusca" & $\begin{array}{l}\text { A palavra "Fusca" (entre aspas) é utilizada nas } \\
\text { publicidades. }\end{array}$ \\
\hline 1970 & Fusca & $\begin{array}{l}\text { Campanha de lançamento 1971 dos carros VW } \\
\text { 1300 e VW 1500. Utilização da palavra Fusca sem } \\
\text { aspas para referir o VW 1300 (setembro). O nome } \\
\text { Fuscão é introduzido na publicidade para } \\
\text { designar o VW 1500. }\end{array}$ \\
\hline
\end{tabular}

Fonte: elaborado pelos autores.

\section{Considerações finais}

Este artigo tomou como foco alguns dos problemas mais relevantes que se podem apresentar quando se trabalha com (ou a partir de) textos históricos. Para isso, exemplificamos nossas considerações observando parte de um percurso de pesquisa realizado sobre a publicidade brasileira de um carro da Volkswagen no período 1950-1970. A esse momento da nossa pesquisa demos o nome de caso "Fusca".

O caso "Fusca" permite mostrar que para a análise de textos históricos em uma perspectiva interacionista que assuma declaradamente a metodologia de abordagem descendente dos textos, torna-se necessária a compreensão do contexto socio-histórico e que para isso não é suficiente consultar bibliografia que tenha abordado mais ou menos o mesmo assunto, mas que é preciso realizar uma busca documental que permita "reconstruir" um certo clima de época. No nosso caso, por exemplo, foi necessário elaborar uma cronologia e periodização própria das formas de denominação do objeto central do estudo. Essa 
cronologia teve, no nosso caso, a sua própria especificidade e, portanto, não coincide necessariamente com as periodizações estabelecidas por outros pesquisadores em relação aos processos políticos, econômicos ou ideológicos (estudos e processos esses que, contudo, sempre devem ser levados em consideração). No nosso caso, a cronologia está ligada à introdução de um determinado carro na sociedade brasileira e as formas de designar esse produto. Assim, para compreender algumas das questões fundamentais do momento e da organização da prática social em causa (a publicitária), tivemos de fazer uma busca em jornais e revistas brasileiras da época. Isso hoje resulta possível pela existência de arquivos online, o que claramente torna o trabalho mais fácil do que em tempos passados.

Retomando os problemas metodológicos de que falamos mais acima, verificamos que um trabalho organizado e sistemático em arquivos institucionais permite evitar alguns dos riscos que mencionamos: a falta de contextualização, a carência de critérios claros para a conformação de um corpus, a (in)certeza da confiabilidade, o olhar anacrônico.

Em suma, observamos que para realizar estudos sobre textos históricos, como no nosso exemplo, é preciso levar em conta dois aspectos principais. Por um lado, para a conformação do corpus da pesquisa, consideramos fundamental a consulta de um determinado arquivo institucional que permita partir de critérios claros para a seleção dos textos e obter dados confiáveis sobre as condições de produção e circulação originais desses exemplares. Por outro lado, para iniciar a análise dos textos do corpus - o que, adotando uma perspectiva descendente, implica conhecer primeiramente as características da situação sócio-histórica de produção e circulação - é necessário não só consultar bibliografia e estudos prévios, mas também explorar documentos disponíveis em jornais e revistas da época. Isto permite reunir informações específicas sobre o objeto de estudo, tal como mostramos com o caso "Fusca".

\section{Referências bibliográficas}

BERNÁRDEZ, Enrique. Teoría y epistemología del texto. Madrid: Cátedra, 1995.

BRICK, Aaron. Fuscões e Golaços: Volkswagen in Brazil. In: 2nd Conference of Brazilian Studies in Northern California. Saint Mary's College of California, 2006. Disponível em: http://citeseerx.ist.psu.edu/viewdoc/download?doi=10.1.1.498.9915\&rep=rep1\&type=pdf.

Acesso em: 15 jul. 2021. 
BRONCKART, Jean-Paul et al. Le fonctionnement des discours. Un modèle psychologque et une méthode d'analyse. Paris: Delachaux et Niestlé, 1985.

BRONCKART, Jean-Paul. Activité langagière, textes et discours. Pour un interactionisme socio-discursif. Lausanne: Delachaux et Niestlé, 1997.

BRONCKART, Jean-Paul. Les genres de textes et leur contribution au développement psychologique. Langages, 153, p.98-108, 2004.

BRONCKART, Jean-Paul. Genres de textes, types de discours et " degrés " de langue. Hommage à François Rastier. Texto! vol. XIII, 1, 2008. Disponível em: http://www.revuetexto.net/docannexe/file/86/bronckart_rastier.pdf. Acesso em: 10 abr. 2013.

FAUSTO, Boris. História do Brasil. São Paulo: EDUSP, 1995.

FERREIRA, Aurélio Buarque de Holanda. Novo Dicionário da língua portuguesa. Rio de Janeiro: Editora Nova Fronteira, 1986.

KOPPER, Christopher. A VW do Brasil durante a Ditadura Militar brasileira 1964-1985. Wolfsburg: Volkswagen Aktiengesellschaft, 2017.

MIRANDA, Florencia. Textos e géneros em diálogo. Uma abordagem linguística da intertextualização. Lisboa: FCG/FCT, 2010.

SERRES, Michel. Polegarzinha. Rio de Janeiro: Bertrand, 2013.

SILVA, Jean Carllo. "O nosso orgulho é nunca ter desapontado você": as propagandas televisivas da Volkswagen e a ditadura militar. Panorama, Goiânia, v. 19. n. 1, p.25-30, 2020.

VOLOSHINOV, Valentin N. El marxismo y la filosofía del lenguaje. Buenos Aires: Godot, 2009 [1929].

WOLFE, Joel. Autos and progress. The brazilian search for modernity. Nova York: Oxford University Press, 2010.

' Doutor e Magister em História Moderna e Contemporânea pelo Instituto Universitário de Lisboa (ISCTE-IUL), Portugal. Professor e pesquisador na Universidade Nacional de Rosario, Argentina.

E-mail die.bussola@gmail.com :

ii Doutora e Pós-doutora em Linguística (Teoria do texto) pela Universidade Nova de Lisboa, Portugal. Professora e pesquisadora na Universidad Nacional de Rosario, Argentina.

E-mail: florenciamiranda7ı@gmail.com

Recebido em 10/10/2021

Avaliado em 30/10/2021 